\title{
Effects of neonatal gonadectomy on DRL behavior
}

\author{
WILLIAM W. BEATTY, CALVIN M. BIERLEY, and JEFFREY M. GERTH \\ Department of Psychology, North Dakota State University, Fargo, North Dakota 58102
}

\begin{abstract}
Gonadectomy on the 1st day of life had no effect on the acquisition of DRL behavior by male rats. Together with other findings, the current results suggest that endogenous androgens are relatively unimportant in the development of sex differences in DRL performance during postnatal life.
\end{abstract}

Adult female rats generally acquire efficient DRL performance more rapidly than males (Beatty, 1973; Kearley, van Hartesveldt, \& Woodruff, 1974). Ovarian hormones are implicated in activating this sex difference in performance since ovariectomy in adulthood depresses efficiency to about the level observed in intact or castrated males. By contrast, testicular hormones seem relatively unimportant in activating the sex difference in DRL behavior because castration has little or no effect on performance by males (Beatty, 1973). As yet the possibility that sex differences in DRL behavior might be influenced by organizational effects of gonadal hormones has not been examined. The present study, which compared the performance of neonatally gonadectomized and control males, was designed to examine this possibility.

\section{METHOD}

\section{Subjects}

The animals were 44 males bred in the laboratory from animals purchased from the Holtzman Company, Madison, Wisconsin. Eleven of the subjects were gonadectomized within $24 \mathrm{~h}$ of birth under hypothermia. The remaining 33 animals, which were littermates of the gonadectomized group, were sham operated at this time. The subjects were reared by their natural mothers until weaning at 21 days of age and caged in groups of 2-3 with free access to food and water until 75 days of age when they were separated into single cages. After ad-lib weights were established, the rats were placed on a restricted feeding schedule designed to maintain body weight at $85 \%$ of the free-feeding weight. This schedule remained in effect for the duration of the experiment. Beginning at 90 days of age, the animals were trained to barpress for 45 -mg Noyes in 1-2 sessions, tested for responding on CRF until they earned 100 reinforcements in a single session, and given 40 daily 30 - sessions on DRL-20 using training and maintenance procedures that are described elsewhere (Beatty, 1973).

\section{RESULTS AND DISCUSSION}

In Table 1 are shown the mean efficiency scores (rein-

Supported by Grant HD 08206 from the National Institutes of Child Health and Human Development.
Table 1

Mean Efficiency Scores $\times 100$ Five-Session Blocks

\begin{tabular}{lrrrrrrrr}
\hline & 1 & 2 & 3 & 4 & 5 & 6 & 7 & 8 \\
\hline $\begin{array}{l}\text { Neonatal } \\
\text { Gonadectomy }\end{array}$ & 5.8 & 5.1 & 8.3 & 8.4 & 9.1 & 11.0 & 13.5 & 14.6 \\
Control & 4.9 & 6.6 & 8.9 & 10.7 & 11.5 & 13.5 & 15.1 & 16.4 \\
\hline
\end{tabular}

forcements/responses) for both groups. Although both groups exhibited slightly improved performance with training, there was no indication that neonatal gonadecttomy affected performance $(F<1)$. By the end of training, both groups were performing considerably less efficiently than adult females tested under comparable conditions in an earlier study (Beatty, 1973). Analyses of the total number of responses made and the number of reinforcements earned also failed to reveal reliable effects of neonatal gonadectomy on performance.

Taken together with earlier findings (Beatty, 1973), the current results indicate that the presence of testicular hormones has little or no effect on the DRL performance of males. The present data also rule out a primary organizational role of testicular androgens, at least during the early postnatal period. It is possible, of course, that androgens acting during the prenatal period might influence sex-typical behavior in the DRL test, or that the actions of androgens during the neonatal period might modify the effects of ovarian hormones on this sexually dimorphic behavior.

\section{REFERENCES}

Beatty, W. W. Effects of gonadectomy on sex differences in DRL behavior. Physiology and Behavior, 1973, 10, 177-178.

Kearley, R. C., van Hartesveldt, C., \& Woodruff, M. L. Behavioral and hormonal effects of hippocampal lesions on male and female rats. Physiological Psychology, 1974, 2, 187-196.

(Received for publication August 19, 1975.) 